\title{
Outcomes from the REACH Registry for Australian general practice patients with or at high risk of atherothrombosis
}

\section{Christopher M Reid BA, MSc, PhD Associate Director \\ Zanfina Ademi MPharm, MPH, PhD, Postdoctoral Research Fellow, \\ Mark R Nelson FRACGP, FAFPHM, PhD, Professor and Head of General Practice ${ }^{3}$ \\ Greg Connor MB BS, FRACP Cardiologist $^{4}$ \\ Derek P Chew MB BS, FRACP Cardiologist $^{5}$ \\ Louise Shiel BSc, GradDipAppSc, GradDipED Manager, Clinical Trials \\ Ana Smeath \\ MNurs, RN, OncCert, Clinical Research Operations Manager ${ }^{6}$ \\ Fred De Looze $\mathrm{MB} \mathrm{BS}^{2}$ \\ Senior Lecturer \\ Ph Gabriel Steg \\ Cardiologist and Director \\ Deepak L Bhatt $\mathrm{MD}, \mathrm{MPH}$, \\ Chief of Cardiology \\ Danny Liew \\ FRACP, PhD Director $^{2}$ \\ on behalf of the REACH Registry Investigators}

ICCRE Therapeutics,

Monash University,

Melbourne, VIC

2 Melbourne EpiCentre University of Melbourne, Melbourne, VIC

3 Discipline of Genera

Practice, University of Tasmania, Perth, TAS

4 Cardiovascular

Diagnostic Services,

Sydney, NSW.

5 Department of

Cardiovascular Medicine

Flinders Medical Centre

Adelaide, SA.

6 Sanofi-aventis

Sydney, NSW.

7 Department of General

Practice, University of Queensland

Brisbane, QLD.

8 Coronary Care Unit,

Bichat Public Hospital,

Paris, France.

9 Brigham and Women's

Hospital and Harvard

Medical School,

Boston, Mass, USA.

chris.reid@monash.edu

MJA 2012; 196: 193-197 doi: 10.5694/mjall.10731 hile the death rate from cardiovascular disease (CVD) continues to decline in Australia, CVD remains the main cause of death (about a third of all deaths) in the community. ${ }^{1,2}$ In the context of Australia's ageing population, the total CVD burden is expected to increase in the coming decades. ${ }^{2}$ With major improvements in acute care, including the implantation of stents and cardiac surgery, many of those who suffer an acute cardiovascular event will survive. Counterbalancing this is the fact that sudden death still accounts for about a quarter of all CVD presentations. ${ }^{2,3}$ It is estimated that 1.4 million Australians are CVD survivors (about $7 \%$ of the population) and the direct health care costs of managing these conditions accounts for $11 \%$ of total health expenditure in Australia. ${ }^{2,4}$ It is well known that those who have overt CVD are at the highest risk of future events. ${ }^{5}$ This group is a key target for secondary prevention strategies aimed at reducing the risk of future events. ${ }^{6}$ It has also been well documented through many large-scale clinical trials that therapeutic management of CVD risk factors in this population yields convincing benefits in terms of reduction in CVD risk. ${ }^{7-9}$ In primary prevention (for people who have not experienced a cardiovascular event), the clustering of three or more CVD risk factors has also been shown to increase the risk of future events. Thus, primary prevention strategies focus on identifying and controlling CVD risk factors in this group. ${ }^{10}$

One of the major health challenges facing contemporary Australian society is controlling the rapid rise in obesity and diabetes in the population. The impact of obesity on CVD risk factors like high blood pressure, dyslipidaemia and diabetes has been well documented. ${ }^{11}$ However, the impact of obesity on major cardio-

Abstract

Objective: To report on 1-year cardiovascular (CV) event rates in patients with established cardiovascular disease (CVD) or with multiple cardiovascular risk factors.

Design, patients and setting: Prospective cohort study of 2873 patients at high risk of atherothrombosis based on the presence of multiple risk factors and overt coronary artery disease (CAD), cerebrovascular disease (CerVD) or peripheral arterial disease (PAD) presenting to 273 Australian general practitioners; this study was conducted as part of the international REACH Registry.

Main outcome measures: One-year rates of cardiovascular death, myocardial infarction, stroke, and hospitalisation for cardiovascular procedures.

Results: The cardiovascular death rate at 1 year was 1.4\%. The combined cardiovascular death, non-fatal MI, stroke and hospitalisation rate for vascular disease affecting one location at 1 year was $11 \%$. Even for patients with no overt disease, but with multiple risk factors, the 1-year combined event rate was $4.2 \%$. The highest combined event rate was in patients with PAD (21.0\%), and in patients with atherothrombotic disease identified in all three locations (coronary arteries, cerebrovascular system and peripheral arteries) at 39\%.

Conclusion: The rate of clinical events in community-based patients with stable atherothrombotic disease increases dramatically with the severity of disease and the number of vascular beds involved. Where disease was evident in all three locations, and for patients with PAD alone, the 1-year risk of cardiovascular events was substantially increased. Poor adherence to statin therapy in the secondary preventive setting is a major treatment gap that needs to be closed; the influences of obesity and diabetes warrant further investigation.

vascular outcomes, in secondary prevention, such as cardiovascular death, non-fatal stroke, non-fatal myocardial infarction, and vascular interventions is more controversial. ${ }^{12}$

While a number of Australian studies have shown that CVD risk factor management in those with existing disease and those at highest risk is suboptimal, there are no data available in Australia to inform on the outcomes for patients being managed for both primary and secondary CVD prevention in general practice. ${ }^{13,14}$ In addition, there is little information to determine the impact of diabetes and obesity on clinical outcomes in patients at risk of and being managed for CVD.

Our aim in this study was to report on the 1-year clinical outcomes for patients being managed for primary and secondary CVD risk reduction in Australian general practice and, in particular, to focus on the impact of diabetes and obesity.

\section{Methods}

\section{The REACH Registry}

The international REACH Registry was an observational longitudinal study of the management of people with, or at high risk of, atherothrombosis. ${ }^{15,16}$ The REACH Registry methods have been published previously. ${ }^{13-15}$ In brief, it recruited 67888 patients in 44 countries across the world. ${ }^{15,17}$ In Australia, 2873 patients were recruited through 273 general practices across the country. Information was collected by medical record review performed by study nurses. To increase the generalisability, each participating general practitioner recruited up to a maximum of 15 consecutive patients.

\section{Study population}

The study population comprised participants aged 45 years or older who had established coronary artery disease (CAD), cerebrovascular disease 
1 Baseline demographics of patients included in the 1-year follow-up analysis

\begin{tabular}{|c|c|c|c|c|}
\hline Variable & $\begin{array}{c}\text { Number of } \\
\text { patients }\end{array}$ & $\begin{array}{l}\text { Follow-up } \\
\text { available } \\
(n=2847)\end{array}$ & $\begin{array}{l}\text { Follow-up } \\
\text { not available } \\
(n=26)\end{array}$ & $P$ \\
\hline \multicolumn{5}{|l|}{ Demographic characteristics } \\
\hline Mean age in years (SD) & 2873 & $72.8(8.87)$ & $71.0(9.81)$ & $<0.001$ \\
\hline Male & 1870 & $65.1 \%$ & $69.2 \%$ & 0.89 \\
\hline \multicolumn{5}{|l|}{ Risk factors } \\
\hline Diabetes & 871 & $30.3 \%$ & $30.7 \%$ & 0.98 \\
\hline Hypertension & 2223 & $77.6 \%$ & $50.0 \%$ & $<0.001$ \\
\hline Hypercholesterolaemia & 2227 & $77.6 \%$ & $73.1 \%$ & 0.85 \\
\hline Obesity (BMI > 30) & 831 & $29.2 \%$ & $34.6 \%$ & 0.55 \\
\hline Current smoker & 197 & $6.8 \%$ & $7.7 \%$ & 0.75 \\
\hline \multicolumn{5}{|l|}{ History of atherosclerotic disease } \\
\hline History of CAD & 2116 & $73.6 \%$ & $80.8 \%$ & 0.41 \\
\hline Stable angina with documented CAD & 986 & $36.0 \%$ & $42.3 \%$ & 0.53 \\
\hline Unstable angina with documented CAD & 316 & $11.7 \%$ & $4.0 \%$ & 0.57 \\
\hline History of MI & 1052 & $37.6 \%$ & $46.0 \%$ & 0.75 \\
\hline History of $\mathrm{PCl}$ & 699 & $24.9 \%$ & $24.0 \%$ & 0.95 \\
\hline History of CABG & 851 & $30.1 \%$ & $30.8 \%$ & 0.92 \\
\hline History of CerVD & 669 & $23.4 \%$ & $11.5 \%$ & 0.16 \\
\hline History of TIA & 332 & $12.6 \%$ & 0 & - \\
\hline History of stroke & 402 & $14.9 \%$ & $12.0 \%$ & 0.93 \\
\hline History of PAD* & 260 & $9.0 \%$ & $11.5 \%$ & 0.66 \\
\hline Claudication and $\mathrm{ABI}<0.9^{\dagger}$ & 79 & $2.7 \%$ & $3.8 \%$ & 0.59 \\
\hline History of peripheral angioplasty/stenting/surgery & 198 & $6.9 \%$ & $7.7 \%$ & 0.46 \\
\hline Claudication and history of amputation & 24 & $0.84 \%$ & 0 & - \\
\hline Any history of symptomatic atherothrombosis & 2567 & $89.3 \%$ & $92.3 \%$ & 0.35 \\
\hline Three risk factors only & 306 & $10.7 \%$ & $7.7 \%$ & 0.63 \\
\hline \multicolumn{5}{|l|}{ Medication use } \\
\hline Aspirin & 1849 & $64.5 \%$ & $53.9 \%$ & 0.26 \\
\hline Other antiplatelet agent & 565 & $19.8 \%$ & $7.7 \%$ & 0.12 \\
\hline Oral anticoagulants & 356 & $12.5 \%$ & $15.4 \%$ & 0.65 \\
\hline Non-steroidal anti-inflammatory drugs & 663 & $23.4 \%$ & $15.4 \%$ & 0.34 \\
\hline Statins & 2265 & $78.9 \%$ & $73.1 \%$ & 0.47 \\
\hline Other lipid-lowering agents & 71 & $2.5 \%$ & 0 & - \\
\hline \multicolumn{5}{|l|}{ Characteristics of general practitioners $(n=273)$} \\
\hline Full-time practice & & $86.6 \%$ & $88.5 \%$ & 0.97 \\
\hline Mean age of investigator in years (SD) & & $49.9(9.7)$ & $53.9(9.5)$ & $<0.001$ \\
\hline Male & & $78.0 \%$ & $88.4 \%$ & 0.23 \\
\hline \multicolumn{5}{|l|}{ Practice location } \\
\hline Urban & & $11.1 \%$ & $7.7 \%$ & 0.84 \\
\hline Suburban & & $70.9 \%$ & $80.7 \%$ & 0.58 \\
\hline Rural & & $16.3 \%$ & $11.5 \%$ & 0.79 \\
\hline
\end{tabular}

$\mathrm{ABI}=$ ankle brachial index. $\mathrm{BMI}=$ body mass index. $\mathrm{CABG}=$ coronary artery bypass graft. $\mathrm{CAD}=$ coronary artery disease CerVD = cerebrovascular disease. $\mathrm{MI}=$ myocardial infarction. $\mathrm{PAD}=$ peripheral arterial disease. $\mathrm{PCl}=$ percutaneous coronary intervention. TIA = transient ischaemic attack.

* Includes symptomatic patients with a history of PAD. † Includes asymptomatic patients.

$P$ values for significant variables are shown in bold.

(CerVD), peripheral arterial disease (PAD) or at least three CVD risk factors. Only patients with established CAD, CerVD or symptomatic PAD were included in any classification of diseases in any vascular beds. In Australia, all participants had ankle brachial index (ABI) measurements taken at baseline, with PAD defined as an ABI of less than 0.9. The measure- ment of ABI was only used to determine whether a participant had a low $\mathrm{ABI}$ as one of the risk factors rather than as established PAD. Therefore, no one was upgraded to being considered to have disease in two or three vascular beds on the basis of an $A B I$ measurement alone. Eligible risk factors were: systolic blood pressure $\geqslant 150 \mathrm{mmHg}$ despite therapy for at least 3 months; dyslipidaemia treated with medication; current smoking of at least five cigarettes per day; age 65 years or older for men and 70 years or older for women; being treated for diabetes mellitus; diabetic nephropathy; $\mathrm{ABI}<0.9$; asymptomatic carotid stenosis of $\geqslant 70 \%$; and carotid intima media thickness of two times or more that of adjacent sites. Participants who were involved in clinical trials or were hospitalised at the time of enrolment were excluded from the registry..$^{13}$ Obesity was defined as a body mass index of $\geqslant 30 \mathrm{~kg} / \mathrm{m}^{2}$.

\section{Clinical event reporting}

Baseline examinations were conducted from 1 March to 30 June 2004, and all participants were followed up through the GP via case note review and interview.

Participants were also re-evaluated at $12 \pm 3$ and $21 \pm 3$ months to ascertain whether they had experienced any clinical events, hospitalisation or a need for other health care services, and to evaluate their medication use. Data were collected centrally with the use of a standardised international case report form from interviews and telephone follow-up.

Events were not independently adjudicated. However, death records and hospital admission records for all reported cardiovascular events were sourced and verified to report clinical outcomes. REACH clinical event definitions have been described in detail elsewhere. ${ }^{16}$ In brief, cardiovascular death included fatal myocardial infarction, fatal stroke and other cardiovascular death, including heart failure. Non-fatal events included non-fatal myocardial infarction, nonfatal stroke, and hospitalisation for cardiac procedures including percutaneous coronary interventions and cardiac surgery.

- $\quad$ The REACH Registry was approved by the Royal Australian College of General Practitioner Research and Ethics Committee (C-8903) and the Institutional Ethics Committee of Monash University. All participants gave their written informed consent.

\section{Statistical analyses}

All statistical analyses were performed using SPSS for Windows, version 15.0 (SPSS Inc, Chicago, Ill, USA). Data were reported as crude 
rates, and $P$ values of less than 0.05 were considered statistically significant. Logistic regression analyses were applied to determine the impact of cardiovascular drugs on clinical outcomes at 1 year. The results were reported as adjusted odds ratios (OR).

Five subgroups of patients with established atherothrombotic disease were defined: CAD, CerVD, PAD and combinations of any of the above (patients with two to three affected vascular beds). The logistic regression models were adjusted for age, sex, disease subgroups and risk-factor group (no CVD).

\section{Results}

Of the 2873 participants enrolled in the Australian REACH Registry, 1year follow-up data were available for 2847. Australia had one of the highest retention rates of all 44 countries participating in the global REACH Registry: 98\% at year $1 .^{16}$ Box 1 shows baseline characteristics for Australian participants included in the 1-year follow-up analysis as well as for those who did not attend for follow-up. No significant systematic differences were observed between those who were and were not followed up at 1 year, with the exception that those who were followed up were slightly older and had a higher prevalence of hypertension. Furthermore, except for the age of investigators, there was no difference in the characteristics of participating GPs. Cardiovascular drug use remained high at 1 year, with $78.6 \%$ taking statins and $63.1 \%$ taking aspirin. However, only $38.6 \%$ were taking $\beta$-blockers. These figures were almost identical to baseline drug use of $78.9 \%, 64.5 \%$ and $37.2 \%$ for the three drugs, respectively.

Overall, the annual death rate was $2.3 \%$ (65 deaths), with cardiovascular deaths accounting for $60 \% \quad$ (39 deaths; $1.4 \%$ overall). The impact of CVD in this group was high, with the annual combined rate for the hard clinical events of cardiovascular death, non-fatal myocardial infarction or stroke ranging from $2.0 \%$ for those with multiple risk factors (Box 2A), $6.6 \%$ for those with PAD (Box 2B) to $14.3 \%$ in those with disease in two to three vascular beds (Box 2A). When hospitalisation for atherothrombotic events was included in a combined end point, these rates increased twoto threefold, being $4.2 \%$ for those with multiple risk factors (Box 2A), $21.0 \%$ for those with PAD (Box 2B) and $39.3 \%$ for those with vascular disease in two to three beds (Box 2A).

\section{Baseline risk factors, overt disease and outcomes}

Box 3 shows event rates with 95\% CIs for patients classified according to their risk factors and overt disease. Obese patients had an event rate of $9.3 \%$ for the combined end points of cardiovascular death, non-fatal myocardial infarction, non-fatal stroke and hospitalisation for atherothrombotic events, versus $10.9 \%$ and $11.6 \%$ in the overweight and normal weight groups, respectively. The highest combined end points and hospitalisation for atherothrombotic events among those without established disease were among patients with hypertension and diabetes $(13.0 \%$ and $11.6 \%$ respectively).

\section{Baseline cardiovascular drug use and 1-year outcomes}

Box 4 shows the event outcomes on the basis of cardiovascular drug use at baseline in this secondary prevention population. Cardiovascular deaths were more likely to occur among patients who did not use statins compared with those who did (OR, 2.1; $95 \%$ CI, 1.1-4.3). Patients who did not use statins were also more likely to experience combined cardiovascular death, non-fatal myocardial infarction and stroke (OR, 2.1; 95\% CI 1.3-3.5).

In adjusted analyses, neither the use of aspirin and at least one antihypertensive agent nor the use of optimal therapy (antihypertensive agent, statin and aspirin) was significantly associated with outcomes.

\section{Discussion}

To our knowledge, this is the first report on "hard" clinical outcomes in patients being managed for CVD risk factors in Australian general practice. For this group of high-risk patients, fatal and non-fatal event rates increased with increasing evidence of diffuse CVD. Patients with PAD
2 Rates of atherothrombotic events* according to number of locations ${ }^{\dagger}$ and type of vascular disease at baseline

A: Event rate according to number of locations of disease at baseline

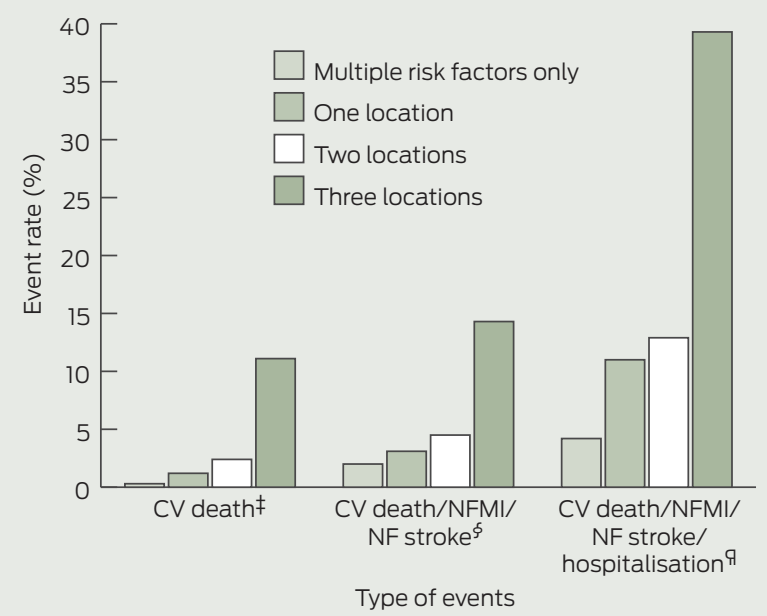

B: Event rate according to type of atherothrombotic disease at baseline

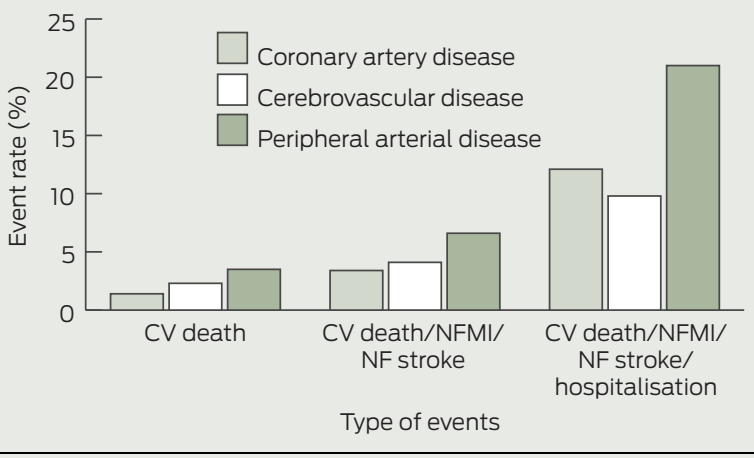

* Including cardiovascular (CV) death, non-fatal myocardial infarction (NFMI), non-fatal (NF) stroke and hospitalisation for atherothrombotic events. † Locations include coronary arteries, cerebrovascular system and peripheral arteries. $\ddagger P<0.01$. $\$ P<0.05$. १ $P<0.001$.

3 One-year event rates* for atherothrombotic events according to their risk factors and overt disease

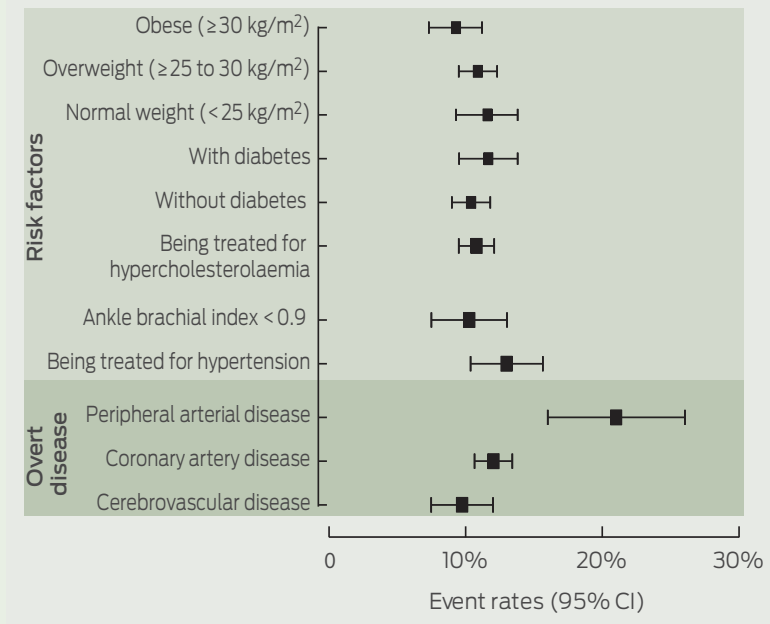

* Including cardiovascular death, non-fatal myocardial infarction, non-fata stroke and hospitalisation for cardiac procedures. 
Cardiovascular drugs

\begin{tabular}{|c|c|c|c|c|c|c|c|c|c|c|c|c|}
\hline \multirow[b]{2}{*}{ Outcome at 1 year } & \multicolumn{3}{|c|}{ Statins } & \multicolumn{3}{|c|}{ Aspirin } & \multicolumn{3}{|c|}{ Antihypertensives } & \multicolumn{3}{|c|}{ Optimal therapy* } \\
\hline & Yes & No & $\mathrm{OR}^{\dagger}(95 \% \mathrm{Cl})$ & Yes & No & $\mathrm{OR}^{\dagger}(95 \% \mathrm{Cl})$ & Yes & No & $\mathrm{OR}^{\dagger}(95 \% \mathrm{Cl})$ & Yes & No & $\mathrm{OR}^{\dagger}(95 \% \mathrm{Cl})$ \\
\hline CV death & $1.1 \%$ & $2.3 \%^{\ddagger}$ & $2.1(1.1-4.3)^{\ddagger}$ & $1.0 \%$ & $2.0 \%^{\ddagger}$ & $1.9(0.9-3.6)$ & $1.4 \%$ & $1.1 \%$ & $0.6(0.1-2.4)$ & $1.0 \%$ & $1.7 \%$ & $1.6(0.7-3.3)$ \\
\hline CV death/Ml/stroke & $2.8 \%$ & $5.3 \% \%^{\S}$ & $2.1(1.3-3.5)^{\ddagger}$ & $3.2 \%$ & $3.7 \%$ & $0.9(0.6-1.4)$ & $3.4 \%$ & $2.4 \%$ & $0.6(0.2-1.6)$ & $2.7 \%$ & $3.9 \%$ & $1.5(0.9-2.4)$ \\
\hline $\begin{array}{l}\text { CV death/MI/stroke/ } \\
\text { hospitalisation }\end{array}$ & $11.0 \%$ & $10.8 \%$ & $0.9(0.7-1.3)$ & $10.7 \%$ & $11.1 \%$ & $1.1(0.8-1.3)$ & $11.4 \%$ & $6.3 \%^{\ddagger}$ & $0.6(0.4-1.1)$ & $11.3 \%$ & $10.5 \%$ & $0.9(0.7-1.2)$ \\
\hline
\end{tabular}

$\mathrm{CV}=$ cardiovascular. $\mathrm{Ml}=$ myocardial infarction .

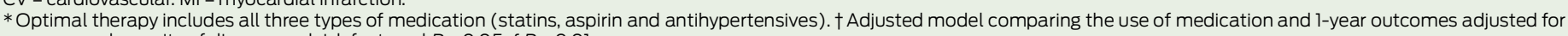
age, sex, and severity of disease and risk factors. $\ddagger P<0.05$. $\$ P<0.01$.

constitute one of the highest risk groups and, while the baseline level of cardiovascular drug treatment is high and on par with specialist medical practice, $^{13}$ those not receiving statin therapy seem to be at substantially increased risk over 1 year for cardiovascular death, non-fatal myocardial infarction and non-fatal stroke.

Previously published Australian $\mathrm{REACH}$ data on the use of drugs among groups with different atherothrombotic diseases showed that patients with PAD used fewer antiplatelet, antihypertensive and lipid-lowering agents. ${ }^{18,19}$ The same observation was made in international REACH Registry data. ${ }^{16,17}$ This may explain the higher risk borne by patients with PAD.

Furthermore, it has been previously reported that in primary care, although the prevalence of PAD is high, awareness of this disease is low. $^{20}$ Asymptomatic PAD can be detected through a relatively simple ABI measurement, and our findings highlight the importance of identifying PAD and managing risk factors in this high-risk group.

The impact of obesity on hard clinical events, in particular cardiovascular death, observed in our prospective analysis is consistent with the "obesity paradox" that has been identified in other populations and cardiovascular studies. ${ }^{21-23}$ For example, in a cohort of outpatients with established heart failure, a higher body mass index was associated with a lower mortality risk; and overweight and obese patients had a lower risk of death than those at a healthy weight. ${ }^{21}$ While these observations have also been reported in patients with hypertension and heart disease, $^{22}$ little is known of the underlying mechanisms, and a better understanding of the obesity paradox $^{24,25}$ is required.

In contrast, the presence of absence of antihypertensive drug therapy showed no significant association with cardiovascular outcomes in this high-risk group, and the trend was an association with worse outcomes. This surprising finding may be the result of confounding, a limited number of stroke events, or may even suggest that, over a year, statin and aspirin therapy may account for the greatest impact on CVD risk.

The impact of diabetes and its consequences in relation to cardiovascular death and illness has been widely promoted in Australia over the past decade. ${ }^{24-26}$ Most guidelines have recommended that diabetes be considered as a coronary risk equivalent, but this has recently been the focus of considerable debate. Our findings are consistent with the observation that, compared with patients with overt CVD, diabetes alone does not have as large an impact on major clinical events. $^{3}$

While the Australian REACH Registry cohort is a subset of the international REACH Registry $3,27,28$ our findings reflect what Australian GPs confront in terms of the clinical outcomes for patients managed for CVD. Clearly, our study has limitations in terms of sample size, and it could be argued that the 273 GPs may not be representative of all GPs in Australia. Selection biases in terms of a potentially more compliant group who are willing to be followed over the 12 months should also be considered in the interpretation of our findings.

In conclusion, the rate of clinical events in community-based patients with stable atherothrombotic disease increases dramatically with the severity of disease and the number of vascular beds involved. Where disease was evident in all three locations (patients with CAD, CerVD and PAD) and for patients with PAD alone, the 1-year risk of cardiovascular events was substantially increased. Poor adherence to statin therapy in secondary prevention is a major treatment gap that needs to be closed, and the influence of obesity and diabetes warrants further investigation.

Acknowledgements: The REACH Registry is sponsored by sanofi-aventis (Paris, France), Bristol-Myers Squibb (Princeton, New Jersey, USA), and the Waksman Foundation (Tokyo, Japan). Sponsors can review manuscript submissions, but do not have authority to change any aspect of a manuscript.

Competing interests: Deepak Bhatt has received research grants from: AstraZeneca, Bristol-Myers Squibb, Eisai, Ethicon, Heartscape, sanofi-aventis, and The Medicines Company. Christopher Reid has received research grants from Servier Australia, sanofi-aventis, Bristol-Myers Squibb and Pfizer. Mark Nelson has received research grants from from SmithKline Beecham, AstraZeneca, Bayer, sanofi-aventis, Merck Sharpe and Dohme, Pfizer, Servier Laboratories and Bristol-Myers Squibb. Danny Liew has received research funding from and has previously consulted for sanofi-aventis. Greg Connor has received payment for previous consultancies, lecturing and educational presentation from Abbott Pharmaceutical, AstraZeneca, Bayer, Boehringer Ingelheim, Bristol-Myers Squibb, GlaxoSmithKline, Eli Lilly, Medimark International, Merck Sharpe and Dohme, Novartis, Pfizer, sanofi-aventis, Schering-Plough, Servier Laboratories and Solvay. Derek Chew has received payment for lecturing, travel, accommodation and meeting expenses from AstraZeneca, Abbott Pharmaceuticals, sanofi-aventis, Pfizer Australia. Gabriel Steg has received a research grant from sanofi-aventis, speakers bureau fees from Boehringer Ingelheim, BristolMyers Squibb, GlaxoSmithKline, Medtronic, Nycomed, sanofi-aventis and Servier, and has received consultancy fees from or been on advisory boards for Astellas, AstraZeneca, Bayer, Boehringer Ingelheim, Bristol-Myers Squibb, Endotis Pharma, GlaxoSmithKline, Medtronic Merck Sharpe and Dohme, Nycomed, sanofi-aventis, Servier and The Medicines Company.

Received 9 Jun 2011, accepted 22 Dec 2011.

1 Australian Institute of Health and Welfare. Heart, stroke and vascular disease: Australian facts 2004. Canberra: AlHW and Heart Foundation of Australia, 2004. (AlHW Cat. No. CVD 27; Cardiovascular Series No. 22). http:// www.aihw.gov.au/publication-detail/?id= 644twofour67598 (accessed Jan 2012).

2 Australian Institute of Health and Welfare. Australia's Health 2008. Canberra: AlHW, 2008. http://www.aihw.gov.au/publication-detail/?id= 6442468102 (accessed Jan 2012).

3 Bhatt D, Eagle K, Ohman M, et al. Comparative determinants of 4-year cardiovascular event 
rates in stable outpatients at risk of or with atherothrombosis. JAMA 2010; 304:1350-1357.

4 Ademi Z, Walls HL, Peeters A, et al. Economic implications of obesity among people with atherothrombotic disease. Int J Obes (Lond) 2010: 34: 1284-1292.

5 Shaper A, Pocock S, Phillips A, Walker M. Identifying men at high risk of heart attacks: strategy for use in general practice. BMJ 1986; 293: 474-479.

6 Kahn R, Robertson RM, Smith R, Eddy D. The impact of prevention on reducing the burden of cardiovascular disease. Circulation 2008; 118: 576-585.

7 Antiplatelet Trialists' Collaboration. Collaborative overview of randomised trials of antiplatelet therapy - I: prevention of death, myocardial infarction, and stroke by prolonged antiplatelet therapy in various categories of patients. BMJ 1994; 308: 81-106.

8 Baigent C, Keech A, Kearney PM, et al. Efficacy and safety of cholesterol-lowering treatment: prospective meta-analysis of data from 90056 participants in 14 randomised trials of statins. Lancet 2005; 366: 1267-1278.

9 Wald N, Law M. A strategy to reduce cardiovascular disease by more than $80 \%$. BMJ 2003; 326: 1419.

10 Jones DW, Peterson ED, Bonow RO, et al. Partnering to reduce risks and improve cardiovascular outcomes: American Heart Association initiatives in action for consumers and patients. Circulation 2009; 119: 340-350.

11 Kumanyika SK, Obarzanek E, Stettler N, et al. Population-based prevention of obesity: the need for comprehensive promotion of healthful eating, physical activity, and energy balance. A scientific statement from American Heart Association Council on Epidemiology and Prevention, Interdisciplinary Committee for
Prevention (Formerly the Expert Panel on Population and Prevention Science). Circulation 2008 July 22, 2008; 118: 428-464.

12 Lancefield T, Clark D, Andrianopoulos N, et al. Is there an obesity paradox after percutaneous coronary intervention $(\mathrm{PCl})$ in the contemporary era? Findings from a large multicentre Australian coronary angioplasty registry. JACC 2010; 3: 660668.

13 Reid C, Nelson MR, Shiel L, et al. Australians at risk: management of cardiovascular risk factors in the REACH Registry. Heart Lung Circ 2008; 17: 114-118.

14 Charles J, Britt H, Ng A. Management of cardiovascular conditions in Australian general practice. Aust Fam Physician 2005; 34: 410-411.

15 Ohman EM, Bhatt DL, Steg PG, et al. The REduction of Atherothrombosis for Continued Health (REACH) registry: an international, prospective, observational investigation in subjects at risk for atherothrombotic events study design. Am Heart J 2006; 151: 786.el-10.

16 Steg PG, Bhatt DL, Wilson PWF, et al. One-year cardiovascular event rates in outpatients with atherothrombosis. JAMA 2007; 297: 1197-1206.

17 Bhatt DL, Steg PG, Ohman EM, et al. International prevalence, recognition, and treatment of cardiovascular risk factors in outpatients with atherothrombosis. JAMA 2006; 295: 180-189.

18 Ademi Z, Liew D, Chew D, et al. Drug treatment and cost of cardiovascular disease in Australia. Cardiovasc Ther 2009; 27: 164-172.

19 Ademi Z, Liew D, Hollingsworth B, et al. Predictors of annual pharmaceutical costs in Australia for community-based individuals with, or at risk of, cardiovascular disease: analysis of Australian data from the REACH registry. Am J Cardiovasc Drugs 2010; 10: 85-94.
20 Hirsch AT, Criqui MH, Treat-Jacobson D, et al. Peripheral arterial disease detection, awareness, and treatment in primary care. JAMA 2001; 286: 1317-1324.

21 Curtis JP, Selter JG, Wang Y, et al. The obesity paradox: body mass index and outcomes in patients with heart failure. Arch Intern Med 2005; 165: 55-61.

22 Uretsky S, Messerli FH, Bangalore S, et al. Obesity paradox in patients with hypertension and coronary artery disease. Am J Med 2007; 120 : 863-870.

23 Gruberg L, Weissman NJ, Waksman R, et al. The impact of obesity on the short-term and longterm outcomes after percutaneous coronary intervention: the obesity paradox? Am J Cardiol 2002; 39: 578-584.

24 Zimmet $P$, Cohen $M$. The diabetes epidemic in Australia: prevalence, patterns and the public health. Med J Aust 1995; 163: 116-117.

25 Carter JN, Bartley PC. The diabetes epidemic in Australia: prevalence, patterns and the public health. Med J Aust 1996; 164: 51.

26 Zimmet PZ, James WPT. The unstoppable Australian obesity and diabetes juggernaut. What should politicians do? Med J Aust 2006; 185: 187-188.

27 Ohman E, BhattD, Wilson P, et al; REACH Registry Investigators. The REACH Registry: an international, prospective, observational investigation in subjects at risk of atherothrombotic events - study design. Am Heart J 2006; 151: 786.

28 Bhatt DL, Steg PG, Ohman EM, et al. International prevalence, recognition, and treatment of cardiovascular risk factors in outpatients with atherothrombosis. JAMA 2006; 295: 180-189. 